\title{
Priscilla Chou
}

\section{香港南亚少数族裔小学生的汉语阅读和朗读}

提要: 南亚裔人士移居香港主要缘于英国的百年贸易和殖民地统治。面对南亚裔 人口的急剧增加, 但南亚裔学生却因汉语能力欠佳而较难升读大学, 南亚裔学 生的汉语教学遂成为香港当今最重要的教育议题之一。近年不少学者已明确指 出, 南亚裔中学生的汉语学习困难以 “写” 为最, “读”次之。但有关香港的南亚 裔小学生的汉语学习困难仍然没有定论。本文通过测试、访谈、观课, 比较 4 个地区 5 所学校 32 位香港南亚裔小三学生在写作和阅读方面的表现, 又透过访 谈、观课考查 10 位研究对象的汉语朗读问题。结果发现对于已掌握一定写字能 力的学生而言, 在阅读方面较写作有更大的 “隐忧”, 而朗读由于不是 “听、 说、读、写”的日常考试范围，在小学阶段没有“朗读”考试，所以更容易被忽 略。文章最后提出一些改善南亚裔学生阅读和朗读表现的建议方法, 希望能有 效提升第二语言教师对学生这两方面 “潜伏” 困难的注意力, 解决学生在阅读和 朗读方面遇上的学习困难。

关键词: 香港, 南亚少数族裔, 小学生, 阅读, 朗读

DOI 10.1515/caslar-2015-0007

\section{1 背景}

南亚裔人士移居香港主要缘于英国的百年贸易和殖民地统治（祁永华 2012）。香 港统计处因着南亚裔人口的大幅增加, 在 1999 年与民政事务局合作, 委托私人 顾问公司进行香港少数族裔人士抽样调查 (民政事务局 2000), 在 2001 年人口 普查起更首次加入有关少数族裔的主题性报告。政府统计处 (2012) 的数字显示, 本港的少数族裔在十年间上升接近 11 万, 从 2001 年的 343,950, 到 2011 年已 达 451,183 人。面对南亚少数族裔人口的急剧增加, 但南亚裔学生却因汉语能力 欠佳而较难升读大学 (立法会 2011c; 政府统计处 2006, 2012a, 2012b), 南亚裔学 生的汉语教学遂成为香港当今最重要的教育议题之一 (从铁华、岑绍基、祁永 华、张群英编着 2012; 黄汝嘉、萧宁波 2009; 谢锡金、祁永华、岑绍基 2012a)。

2012 年, 香港融乐会曾联同香港教育专业人员协会合办有关本港少数族裔 学童学前教育情况的问卷调查 (Hong Kong Unison Limited 2012), 结果发现本

Priscilla Chou, 香港中文大学文学院文学士, 香港大学文学院文学硕士, 香港大学教育学院博 士候选人。研究兴趣主要为中国语文及文学、第二语言教学、南亚少数族裔的汉语学习、信息 科技辅助汉语教学。

电子邮件: choupwy@hku.hk

通讯地址: 香港薄扶林道香港大学教育学院明华综合大楼 604 室 
港的少数族裔学前幼童的学习问题并没有受到足够的关注。然而本港少数族裔小 学生在以本地课程为主的主流学校中就学, 是否只能 “随班混读” (香港融乐会 2011: 4), 无法理解和掌握 “老师于课堂上所教授的内容” (香港融乐会 2011: 4), 最后在汉语的听、说、读、写各方面都跟不上进度, “融合教育” (integrated education) (Education Bureau 2011), 到头来 “只是一场戏” (霍立德 2013)?

2013 年初, 香港圣公会麦理浩夫人中心少数族裔服务部（下简称 “麦理浩夫 人中心”) 开始筹备“本港少数族裔小学学童教育情况调查” (香港圣公会麦理浩 夫人中心 2013)。研究自 2013 年 4 月 27 日开展, 到 2012/13 学年暑假终结。期 间以随机抽样形式, “每七抽一”的访问了全港 70 多所小学, 具体数字及相关材 料请参附录中的表十至十二。

根据该随机抽样访问的结果, 发现本港少数族裔小学学童在汉语的听、

说、读、写四方面虽然以“写”困难最大，然而 “阅读” 和 “朗读” 的困难却较少 为学者所关注。

\section{2 文献回顾}

香港有关南亚裔学生的汉语教与学问题虽然近年来备受关注, 但是却仍属于起 步阶段 (岑绍基 2012b)。虽然过去数年在大学、中、小学、教育团体、社福机构 和教育局等的努力下取得丰硕的成果 (谢锡金、祁永华、岑绍基 2012: xv-xvii), 但惠及的主要为中学、高小及幼儿园的南亚裔学童 (Tse et al 2012)。

尽管语文教育及研究常务委员会（简称“语常会”）(2012) 在 2012 年起资助大 量南亚裔幼儿及初小学生的汉语课外辅导, 香港融乐会 (2011) 及个别学者 (Connelly, Gube, Thapa 2013; 关之英 2008b, 2010; 关之英、马帼英 2009; 黄敏港 2012; 李浚龙 2010) 亦就初小学生的汉语学习投放大量资源, 但是受惠的只有极 少数传统上录取较多南亚裔学生的小学。更不幸的是个别帮助南亚裔小学生学习 汉语的计划因为资源分配的问题而被迫腰斩 (香港融乐会 2011)。

正因香港南亚裔学生汉语学习的研究较少注意小学生的学习, 有关香港的 南亚裔小学生的汉语学习困难仍然没有定论。比方南亚裔中学生面对的 “写作困 难” (岑绍基 2012; 岑绍基、戴忠沛 2013; 岑绍基、张燕华、张群英、祁永华、吴 秀丽 2012) 是否同样是南亚裔小学生面对的最大学习困难? 南亚裔小学生的汉语 程度是否普遍较同龄的本港学童相去几年, 六年级学生只达二、三年级的程 度, 四年级的学生只达一年级的程度 (Wong 2010; 关之英 2008; 黄汝嘉、萧宁 波 2009; 袁振华 2007)? 这将是值得我们再作探讨的问题。

南亚裔中学生面对的 “写作困难” 几乎是听、说、读、写四方面中公认的最大 困难 (岑绍基、张燕华、张群英、祁永华、吴秀丽 2012; 容运珊 2013a, 2013b)。然 而根据 “麦理浩夫人中心” 的报告所指, 从正面提问南亚裔小学生 “最佳” 的汉语 表现时有以下发现: 
“阅读方面的表现同样值得关注, 因为以阅读表现最差或接近最差的数字高达九 成 $(75 \%+14.71 \%=89.71 \%)$ ，与写作表现最差或接近最差的九成五 $(79.41 \%+$ $15.63 \%=95.04 \%$ ) 其实相差无几。” (香港圣公会麦理浩夫人中心 2013：46)

该报告又进一步指出: “以 “其他” 为听、说、读、写以外“尤有更差者”竟占 该项的 $100 \%$ 。受访者所言的“其他”指的正是朗读课文（第 5、20、458 号问 卷)。由是观之, 课文朗读其实是一个容易被忽略的项目, 不少少数族裔(非华 语) 学童对于课文朗读望而却步, 表现较听、说、读、写更值得忧虑。”(香港圣 公会麦理浩夫人中心 2013: 46)

为了提升可信度, 该研究又设置逆向问题, 从反面访问教师有关南亚裔小 学生“最差”的汉语表现, 当中有关“阅读”的问题似乎更为显着, 阅读和写作之 间的差别只有 $0.8 \%$ :

“如果以写作最差或接近最差的数字与阅读的相关数字作一比较, 前者为 $94.38 \%(85.29 \%+9.09 \%)$, 后者为 93.58\% $(11.76 \%+81.82 \%)$, 则可推论出其实 阅读表现不佳的情况虽较写作略逊一筹, 但却往往较容易被忽略, 或置于写作 之下，成为“潜藏”的隐患。” (香港圣公会麦理浩夫人中心 2013： 51)

根据 Jim Cummins 自 1990 年代以来提出的基本人际沟通技巧 (basic interpersonal communication skills, BICS) 与学术能力 (cognitive / academic language proficiency, CALP) (Cummins, 1994; Leung, 2003, 2007; Poon, 1998, 2000) 之别, 听、说属于较易掌握的沟通技巧, 而读、写则属于较难学习的学术 能力。如果“阅读”是潜藏隐患，那“朗读”会不会是更严重的隐患呢？因为“朗 读”虽然属于“说”的范畴, 但是说出来的却是和阅读文字无异的“学术用语”。这 些问题，均是本文希望加以探讨的。

\section{3 研究架构}

本文采用的研究架构是 “麦理浩夫人中心” 的随机抽样的定量研究。该研究在 “本港少数族裔学童学前教育情况的问卷调查” (Hong Kong Unison Limited 2012) 的基础上拟定以本港小学为研究对象的问卷初稿, 在 2013 年 4 月 27 日至 2013 年 5 月中旬先邀请 10 所小学就问卷内容提出意见, 并根据受访者回应修订问卷 内容。期间又根据家庭与学校合作事宜委员会 (2012)《小学概览》的小学名单整 理出全港 516 所小学的资料, 以 “每七抽一” 的形式随机抽样, 再以电话访问的 方法邀请学校接受访问, 由研究者实时填写问卷。

本文以 “麦理浩夫人中心” 的随机抽样定量研究为基础, 先征得该中心的同 意, 然后再以方便取样的形式邀请 28 所小学就报告提供意见, 并成功访问了 21 所学校的教师作深入访谈, 最后再从 21 所学校中邀请 5 所小学 32 位小学三 年级南亚裔学生试做 2012 年 “全港性系统评估” 阅读卷、10 位試做写作卷及接 受访谈, 以及在其中3所小学观察4位学生的语文课堂。 
研究流程如图一:

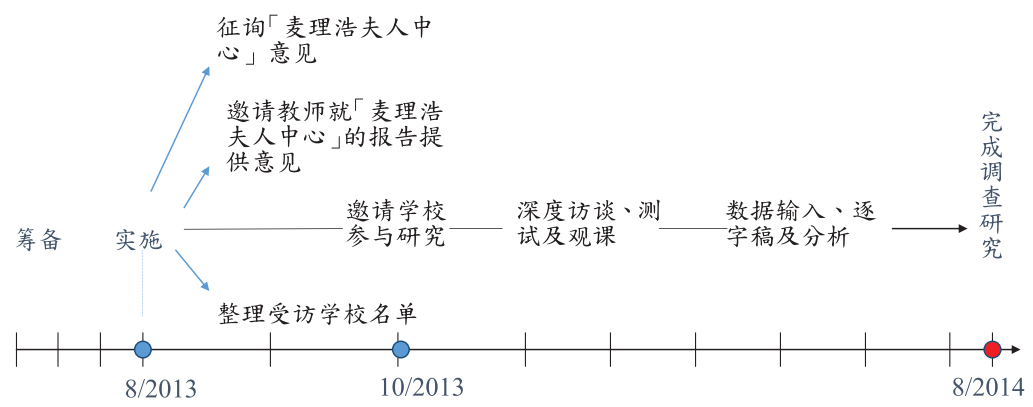

图一: 研究架构

\section{4 研究目的}

根据文献显示, 南亚裔中学生面对的写作难题几乎是听、说、读、写四方面中公 认的最大困难 (岑绍基、张燕华、张群英、祁永华、吴秀丽 2012; 容运珊 2013a, 2013b)，然而这种最大困难是否也适用于南亚裔小学生? “麦理浩夫人中心” (2013) 的访问结果显示南亚裔小学生的阅读问题比写作更值得忧虑, 然而只有访问, 没 有实际测试和观察, 难以证实南亚裔小学生在中文科的最大困难在阅读而不在写 作。本文目的在透过测试、观察和深入访谈考查香港南亚裔小学生在阅读和写作 方面的困难, 以及他们在听、说、读、写以外是否面对其他的学习困难。

\section{5 研究问题}

本文的问题如下:

香港南亚裔小学三年级学生在阅读和写作方面有何表现?

香港南亚裔小学生是否面对“朗读”的困难？如何有效解决学生的学习困难？

\section{6 调查方法}

\section{1 调查取样对象}

本文调查取样的对象为香港 21 所录取南亚裔学生的小学。有关学校的资料见表 一、表二、表三: 
表一: 受访学校简表

\begin{tabular}{ll}
\hline 学校 & 数目 \\
\hline 已联络小学 & 28 \\
成功访问数字 & 26 \\
有录取南亚裔学生的学校 & 21 \\
除访问外尚提供书面回应 & 4 \\
南亚裔学生人数 & $1-503$ \\
全校人数 & $186-934$ \\
南亚裔学生所占比例 & $0.1 \%-100 \%$ \\
受访者 & 主管/校长: 2 \\
& 副校长: 4 \\
& 教务主任: 1 \\
& 课程统筹主任: 1 \\
& 中文科科主任: 12 \\
& 中文科老师: 1 \\
\hline
\end{tabular}

表二: 受访学校地区分布

\begin{tabular}{lclr}
\hline 受访学校地区分布 & 数目 & 受访学校地区分布 & 数目 \\
\hline 中西区 & 5 & 沙田区 & 1 \\
南区 & 2 & 葵青区 & 2 \\
观塘区 & 1 & 荃湾区 & 1 \\
深水埗区 & 2 & 屯门区 & 3 \\
油尖旺区 & 2 & 元朗区 & 1 \\
北区 & 1 & & \\
总数 & & & 21 \\
\hline
\end{tabular}

表 三: 受访学校南亚裔学生百分比

\begin{tabular}{|c|c|c|c|c|c|}
\hline 学校代号 & 南亚裔学生人数 & 全校学生人数 & 男女比例 & 受访者 & 百分比 \\
\hline 158 & 1 & 833 & 1 女 & 中文科科主任 & 0.120048 \\
\hline 363 & 1 & 691 & 1 女 & 教务主任 & 0.144718 \\
\hline 419 & 1 & 610 & 1男 & 副校长 & 0.163934 \\
\hline 481 & 2 & 902 & 1 男 1 女 & 副校长 & 0.221729 \\
\hline 78 & 2 & 662 & 2 男 & 中文科科主任 & 0.302115 \\
\hline 79 & 3 & 908 & 1 男 2 女 & 中文科老师 & 0.330396 \\
\hline 3 & 2 & 555 & 2 女 & 中文科科主任 & 0.36036 \\
\hline 13 & 4 & 934 & 4 女 & 中文科科主任 & 0.428266 \\
\hline 5 & 2 & 259 & 2 女 & 副校长 & 0.772201 \\
\hline 277 & 4 & 504 & 3 男 1 女 & 副校长 & 0.793651 \\
\hline
\end{tabular}


表三: (Continued)

\begin{tabular}{lrrlll}
\hline 学校代号 & 南亚裔学生人数 & 全校学生人数 & 男女比例 & 受访者 & 百分比 \\
\hline 15 & 5 & 502 & 未能提供 & 校长 & 0.996016 \\
6 & 7 & 487 & 7 男 & 中文科科主任 & 1.437372 \\
300 & 6 & 396 & 未能提供 & 中文科科主任 & 1.515152 \\
275 & 5 & 186 & 4 女 1 男 & 中文科科主任 & 2.688172 \\
448 & 30 & 300 & 15 男 15 女 & 课程统筹主任 & 10 \\
387 & 72 & 720 & 未能提供 & 中文科科主任 & 10 \\
237 & 65 & 550 & 未能提供 & 中文科科主任 & 11.81818 \\
458 & 28 & 200 & 16 男 12 女 & 中文科科主任 & 14 \\
214 & 399 & 420 & 未能提供 & 学校主管 & 95 \\
390 & 503 & 525 & 未能提供 & 中文科科主任 & 95.80952 \\
446 & 312 & 312 & 176 男 136 女 & 中文科科主任 & 100 \\
\hline
\end{tabular}

正如表三所示, 21 所参与学校录取的南亚裔学生数量不一, 个别学校更只有 1 名 南亚裔学童。换言之, 不是每所学校也有同一级别的南亚裔学生可供测试。为统 一及公平起见, 调查在访问十一区 21 所学校的代表后, 再从其中四区选出 5 所 学校, 当中既包括南亚裔学生比例只有低于 0.5 百分比的学校, 也有高于 90 百 分比的学校。然后邀请 5 所学校里合共 32 位南亚裔小三学童为研究对象, 族裔 包括：巴基斯坦、菲律宾、印度和日本（日本籍的参与者只有一名）。

\section{2 调查方法}

本文的调查分为四个部分, 即教师访谈、全港性系统评估 (Territory-wide System Assessment, TSA)、学生访谈、观课。

\subsection{1 教师访谈}

研究先约见21位小学代表（详情参表一）, 进行约 30-45 分钟的访谈。再征询教 师、校长、家长及学生的同意, 邀约其中 5 所学校 32 位学生接受全港性系统评 估模拟测试。

\subsection{2 全港性系统评估 (Territory-wide System Assessment, TSA)}

研究者与 5 所学校的教师商议后, 选出 5 校不曾让学生试做的全港性系统评估阅读 卷 2012_3CR2 及写作卷 2012_3CW1。32 位学生均接受阅读卷模拟测试, 其中 10 位 学生同时接受阅读及写作卷模拟测试。阅读卷由于有标准答案, 故由研究者自行 批改。写作卷则邀请两位资深教师作评卷员, 一男一女, 两人均有教育硕士或以 上学历, 评卷员甲已任小学汉语科教师 13 年, 评卷员乙则有 6 年相关教学经验。 
为保障学校及学生私隐, 所有学校及学生名称均以甲乙丙丁或数字代替, 个别接受写作卷模拟测试及访谈的学生则隐去真实姓名, 改以化名显示。

\subsection{3 学生访谈}

研究者在学生接受写作卷模拟测试后邀请学生作跟进访谈, 由于只有 10 位学生 接受写作卷模拟测试, 故访谈的学生也只有 10 名。

\subsection{4 观课}

全港性系统评估测试只能回答第一条研究问题, 故在模拟测试及相关访谈结束 后, 研究者再邀请 5 所学校中的其中 3 所学校参与另一部分的考查, 在 10 位参 与写作卷模拟测试中的其中 4 位小三学生课堂上观课, 以进一步考查学生在阅 读、写作及朗读方面的表现。观课后, 4 位学生均于放学后再接受约 20 分钟的 访谈, 相关教师则于同日或隔日接受约 30 分钟的访谈。

\section{7 调查结果}

\section{1 教师访谈}

教师访谈的内容包括两部分, 第一部分以 21 所学校的代表为对象, 先以 “麦理 浩夫人中心”的问卷 (参附录一) 作引入, 以便确认南亚裔学童在学校的学习情 况。然后再集中询问南亚裔学童的日常表现, 包括听、说、读、写、朗读等, 尤其重视学生的阅读、写作、朗读的能力、兴趣和信心。第二部分的访谈是在 观课以后, 因为只有 4 位学生参与, 故受访教师也只有 4 位。访谈内容主要为 受观察学生对听、说、读、写、朗读的看法; 受观察学生在课堂上的表现、与 其他华裔学生相处的情况, 以及日常的表现与观课时的表现是否一致等等。

教师访谈之阅读和写作的结果, 见表四。

表四: 教师访谈之阅读和写作

\begin{tabular}{lr}
\hline 教师意见 & 人数 \\
\hline 认为少数族裔学生表现最差的是阅读 & 5 \\
认为少数族裔学生表现最差的是写作 & 8 \\
认为少数族裔学生表现最差的是阅读及写作 & 8 \\
总数 & 21 \\
\hline
\end{tabular}


教师访谈节录 (1):

教师甲：其实他.......我自己去写一篇文章, 我......我可以按自己会的来写, 但是 别人拟定的阅读理解, 我就无法完成了。我是说学生的理解能力, 一 定比写作能力低。

研究者: 您的意思是, 学生可以写他喜欢写, 或懂得写的, 但是要理解一些文 章就.......

教师甲: 比写作还难。

研究者: 比写作还难。

教师甲：因为写作可以选择, 选他会用的词儿啊! 不会写美丽就写漂亮呗, 但 是阅读就没有选择, 他看不懂“美丽”就不明白文章内容, 就不懂怎样 回答问题啊！

教师访谈之说话和朗读的结果, 见表五。

表五: 教师访谈之说话和朗读

\begin{tabular}{lr}
\hline 教师意见 & 人数 \\
\hline 认为少数族裔学生说话表现有问题的 & 3 \\
认为少数族裔学生朗读表现有问题的 & 11 \\
认为少数族裔学生说话和朗读表现都没有问题 & 15 \\
认为少数族裔学生说话和朗读表现都有问题 & 6 \\
总数 & 35 \\
\hline
\end{tabular}

*受访者只有 21 人, 但教师可重复选择。

教师访谈节录 (2):

教师甲: 我们不能要求他们发音很标准的, 香港人也有懒音啊!

教师乙: 很少让他们单独朗读, 一般是全班朗读的。

教师丙: 他们不敢独个儿朗读的。

教师丁: 全班都会走音, 不会取笑, 反正大家也一样, 要求不高的话, 说话是 可以的, 朗读的话就很容易读错了!

\section{2 全港性系统评估阅读卷模拟试成绩}

研究者与 5 所学校的教师商议后, 选出 5 校不曾让学生试做的全港性系统评估 阅读卷 2012_3CR2, 32 位学生均接受阅读卷模拟测试。阅读卷由于有标准答 案, 故由研究者自行批改。测试结果如表六所示: 
表六: 阅读卷模拟试成绩

\begin{tabular}{|c|c|c|}
\hline 学校 & 学生 & 得分 \\
\hline A & 小红 & $8 / 24$ \\
\hline B & 小玉 & $19 / 24$ \\
\hline B & 小云 & $7 / 24$ \\
\hline B & 小晴 & $6 / 24$ \\
\hline B & 小宝 & $7 / 24$ \\
\hline C & 小政 & $4 / 24$ \\
\hline$C$ & 小蘅 & $6 / 24$ \\
\hline D & 小怡 & $3 / 24$ \\
\hline D & 小溶 & $2 / 24$ \\
\hline D & D01 & $1 / 24$ \\
\hline D & D02 & $7 / 24$ \\
\hline D & D03 & $1 / 24$ \\
\hline D & D04 & $3 / 24$ \\
\hline D & D05 & $3 / 24$ \\
\hline D & D06 & $3 / 24$ \\
\hline D & D07 & $4 / 24$ \\
\hline D & D08 & $2 / 24$ \\
\hline D & D09 & $3 / 24$ \\
\hline D & D10 & $4 / 24$ \\
\hline D & D11 & $4 / 24$ \\
\hline D & D12 & $2 / 24$ \\
\hline D & D13 & $3 / 24$ \\
\hline D & D14 & $7 / 24$ \\
\hline D & D15 & $3 / 24$ \\
\hline D & D16 & $4 / 24$ \\
\hline D & D17 & $4 / 24$ \\
\hline D & D18 & $4 / 24$ \\
\hline D & D19 & $2 / 24$ \\
\hline D & D20 & $7 / 24$ \\
\hline D & D21 & $8 / 24$ \\
\hline D & D22 & $7 / 24$ \\
\hline D & D23 & $2 / 24$ \\
\hline $\mathrm{E}$ & 湘儿 & $19 / 24$ \\
\hline
\end{tabular}

\section{3 全港性系统评估写作卷模拟试成绩}

研究者与 5 所学校的教师商议后, 选出 5 校不曾让学生试做的全港性系统评估 写作卷 2012_3CW1, 在 32 位接受阅读卷模拟测试的学生中, 只有 10 位同时接 受写作卷模拟测试。写作卷由于没有标准答案, 故邀请了两位资深教师作评卷 
员。有关测试成绩如表七所示, 有关学生写作卷的答题实例见图二。此外, 为 方便下文讨论, 10 位同时接受阅读和写作卷模拟测试的学生背景和测试表现已 整理为表八。

表七: 写作卷模拟试成绩

\begin{tabular}{|c|c|c|c|c|c|c|c|}
\hline \multirow[t]{2}{*}{ 学校 } & \multirow[t]{2}{*}{ 学生 } & \multicolumn{2}{|l|}{ 书信得分 } & \multicolumn{2}{|l|}{ 作文得分 } & \multicolumn{2}{|l|}{ 全卷分数 } \\
\hline & & 评卷员甲 & 评卷员乙 & 评卷员甲 & 评卷员乙 & 评卷员甲 & 评卷员乙 \\
\hline A & 小红 & $20 / 30$ & $12 / 30$ & $35 / 70$ & $33 / 70$ & 55 & 45 \\
\hline B & 小宝 & $0 / 30$ & $0 / 30$ & $35 / 70$ & $36 / 70$ & 35 & 36 \\
\hline B & 小玉 & $20 / 30$ & $18 / 30$ & $53 / 70$ & $34 / 70$ & 73 & 52 \\
\hline B & 小云 & $0 / 30$ & $0 / 30$ & $46 / 70$ & $33 / 70$ & 46 & 33 \\
\hline B & 小晴 & $0 / 30$ & $0 / 30$ & $49 / 70$ & $35 / 70$ & 49 & 35 \\
\hline C & 小政 & 99\% 英文 & & 全英文 & & $\mathrm{N} / \mathrm{A}$ & \\
\hline C & 小蘅 & 全英文 & & 全英文 & & $\mathrm{N} / \mathrm{A}$ & \\
\hline D & 小怡 & 全英文 & & 全英文 & & $\mathrm{N} / \mathrm{A}$ & \\
\hline D & 小溶 & 全英文 & & 全英文 & & $\mathrm{N} / \mathrm{A}$ & \\
\hline$E$ & 湘儿 & $23 / 30$ & $18 / 30$ & $52 / 70$ & $33 / 70$ & 75 & 51 \\
\hline
\end{tabular}

\begin{tabular}{|c|c|c|c|c|c|c|c|c|c|c|c|}
\hline \multirow{15}{*}{$r$} & & & 但3 & 基月 & 的 & 日走 & 化妾 & & 我 & 和 & \\
\hline & 可 & $\bar{\sigma}$ & $\not 1$ & 王们 & 心 & 固 & $\exists \overline{0}$ & 要 & & ह & \\
\hline & $\bar{s}$ & 白日 & $b_{0}$ & 24 & 济奇 & 零 & & 我 & $\sqrt{2}$ & 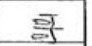 & \\
\hline & हा & 咅它 & $\therefore$ & $\Gamma$ & 我 & 칭 & 主元 & D阿 & 1 & $j$ & \\
\hline & 큭 & 可 & 言兑 & $\therefore$ & $\Gamma$ & 女子 & $D \beta \bar{~}$ & \pm & ) & & \\
\hline & & & 我 & 洷门 & $\sqrt{z_{2}}$ & 急 & & 文䴁 & रे勇 & 言范 & स्येत्र \\
\hline & 我 & 作日 & 要 & $z_{1}$ & 探 & 亲貝2 & 龙 & वाउन & $\therefore$ & ) & \\
\hline & 我 & 言 & $\therefore$ & $r$ & $\frac{13}{3}$ & $\triangle B A$ & 1 & 1 & & 我 & \\
\hline & 僻 & $z_{1}$ & 韭捗 & 他 & 童見 & 友 & 家 & 裹 & & 金 & \\
\hline & 备 & 禾足 & 文要 & 女时 & 莫 & $J$ & 京禁 & 45 & & 212.5 & 100 \\
\hline & 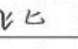 & 他 & 齐击 & 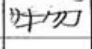 & 0 & 化 & 从L司 & 我 & IfI & $e$ & , \\
\hline & 我 & 言临 & $=1$ & $\Gamma$ & 身 & 罢䊦 & 健聿 & 康 & 4 & 大 & \\
\hline & 志 & 大 & 条师 & $\triangle B J$ & 1 & 1 & 他 & $\doteq \frac{\text { oै }}{5}$ & $=$ & $\Gamma$ & \\
\hline & 重 & ब्रैe & 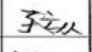 & 7 & - $\mathrm{F}$ & 1 & $\pi$ & $\square$ & 恎(1) & 家 & \\
\hline & 焉 & 琞 & 然工 & 'es, & 来 & IID & 有 & \pm & + & 元 & iso \\
\hline
\end{tabular}

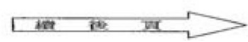

图二: 写作卷模拟试示例 
表八: 阅读、写作成绩比较及访谈对象背景

\begin{tabular}{|c|c|c|c|c|c|c|c|c|c|}
\hline \multirow[t]{2}{*}{ 学校 } & \multirow[t]{2}{*}{ 学生 } & \multirow[t]{2}{*}{ 性别 } & \multirow[t]{2}{*}{ 族裔 } & \multirow[t]{2}{*}{ 年龄 } & \multirow[t]{2}{*}{ 在港出生 } & \multirow[t]{2}{*}{ 幼儿园 } & \multirow{2}{*}{$\frac{T S A \text { (读) }}{24 \text { 分满分 }}$} & \multicolumn{2}{|r|}{ TSA (写) } \\
\hline & & & & & & & & 评卷员甲 & 评卷员乙 \\
\hline A & 小红 & 女 & 菲律宾 & 9 & $\checkmark$ & 汉语 & 8 & 55 & 45 \\
\hline B & 小玉 & 女 & 巴基斯坦 & 9 & $\checkmark$ & 汉语 & 19 & 73 & 52 \\
\hline B & 小云 & 女 & 巴基斯坦 & 9 & $\mathrm{x}$ & 汉语 & 7 & 46 & 33 \\
\hline B & 小晴 & 女 & 巴基斯坦 & 10 & $\mathrm{x}$ & 英语 & 6 & 49 & 35 \\
\hline B & 小宝 & 男 & 巴基斯坦 & 9 & $\checkmark$ & 汉语 & 7 & 35 & 36 \\
\hline C & 小政 & 男 & 印度 & 9 & $\checkmark$ & 英语 & 4 & N/A $(9$ & \% 英) \\
\hline C & 小蘅 & 女 & 日本 & 9 & $\mathrm{x}$ & 英语 & 6 & $\mathrm{~N} / \mathrm{A}(\hat{\mathrm{s}}$ & \\
\hline D & 小怡 & 男 & 印度 & 8 & $\checkmark$ & 英语 & 3 & $\mathrm{~N} / \mathrm{A}$ (全 & 英) \\
\hline D & 小溶 & 男 & 印度 & 9 & $\checkmark$ & 汉语 & 2 & $\mathrm{~N} / \mathrm{A}$ (全 & \\
\hline E & 湘儿 & 女 & 菲律宾 & 10 & $\checkmark$ & 汉语 & 19 & 75 & 51 \\
\hline
\end{tabular}

\section{4 学生访谈及观课}

研究者除了访问 10 位接受写作卷模拟测试的学生外, 亦观察了其中 4 位学生的语 文科课堂表现。适逢其中一所学校为文化日, 所有学生均参加班际朗读比赛, 以 小组形式进行, 每组 2-4 人。故连同文化日的课堂观察, 合共有 5 次观课安排。

学生访谈的内容包括两部分, 第一部分以 10 位接受写作卷模拟测试的学生为 对象, 先以全港性系统评估阅读卷 2012_3CR2 及写作卷 2012_3CW1 作引入, 确认 受访者对测试难易度的看法。然后再集中询问受访者的日常表现，包括听、说、 读、写、朗读等, 尤其重视学生的阅读、写作、朗读的能力、兴趣和信心。第二 部分的访谈是在观课以后, 因为只有 4 位学生参与, 故受访者也只有 4 位。访谈 内容主要为受观察学生在课堂上的表现、与其他华裔学生相处的情况, 以及日常 的表现与观课时的表现是否一致等等。表九的访问问题每一回均会出现，但为了 不影响受访者回答时的准确度, 有时候会按受访者的反应调整问题的顺序。

学生访谈结果如下:

表九: 学生访谈结果

\begin{tabular}{lll}
\hline & $\checkmark$ & $\mathbf{X}$ \\
\hline 你害怕朗读吗? & 5 & 5 \\
你害怕自己一个人朗读吗? & 7 & 3 \\
你害怕和全班同学一起朗读吗? & 2 & 8 \\
你对朗读有信心吗? & 4 & 6 \\
你对自己一个人朗读有信心吗? & 3 & 7 \\
你对和全班同学一起朗读有信心吗? & 9 & 1 \\
你喜欢朗读吗? & 2 & 8 \\
你喜欢自己一个人朗读吗? & 3 & 7 \\
你喜欢和全班同学一起朗读吗? & 6 & 4 \\
\hline
\end{tabular}


为了进一步考究研究对象的 “朗读” 表现, 研究者在访问 21 位教师、邀请 32 位学生接受模拟测试及邀请 10 位学生作访谈后, 又观察了 4 位学生的课堂表 现, 并在观课后再作跟进访谈。根据观课所得, 4 位研究对象中有 3 位对 “朗 读” 颇为抗拒, 尤其害怕单独朗读, 原因是担心自己的发音不够准确, 会被同 学取笑。以杜牧《山行》一诗为例:

远上寒山石径斜, 白云深处有人家。停车坐爱枫林晚, 霜叶红于二月花。

研究对象朗读四句诗句, 每句均有一个字发音错误。

其中两位受访者的访谈节录如下:

访谈节录 (1)

学生甲: 我最差, 是读。

研究者: 是阅读还是朗读?

学生甲: 一样差!

研究者: 你觉得怎么样可以提升自己的阅读和朗读能力?

学生甲: 我想参加朗诵比赛!

访谈节录 (2)

研究者: 你刚刚念书, 朗读出来, 怕不怕?

学生乙: 很怕!

研究者: 怕同学还是怕老师?

学生乙: 很怕同学啊!

研究者: 不怕老师吗?

学生乙：当然更怕啊！干什么要我念嘛！

研究者: 你觉得自己是香港人吗?

学生乙: 我是菲律宾人, 我干么要念汉语?

\section{8 讨论}

本文主要希望透过量化的测试成绩和质化的访谈、观课活动, 考查香港南亚裔 小学生在阅读和写作方面的困难, 是否真如 “麦理浩夫人中心” (2013) 的研究所 言, 阅读和朗读是这些学生潜藏的困难。经过对前文调查结果的分析, 我们试 着来回答这些问题。

\section{1 研究问题一的初步解答}

研究问题一: 香港南亚裔小学三年级学生在阅读和写作方面有何表现? 
首先, 先从教师访谈的结果加以分析。根据表四所示, 教师认为南亚裔小学 生的写作表现比阅读更差的有 8 人, 而认为后者较前者弱的只有 5 人, 可见大 部分教师在受访时并没有明确指出阅读较写作更困难。但是让人发人深省的是 指出阅读和写作同样困难的受访教师同样有 8 名, 可见南亚裔小学生在阅读方 面的困难纵然不是较写作更甚, 但也几乎可以等量齐观。

再者, 根据全港性系统评估阅读和写作卷的模拟测试结果看来, 32 位小三 学生的阅读成绩明显并不理想, 32 人中只有两人及格, 及格率只有 $6.25 \%$ 。反 观写作方面的表现, 虽然参与模拟测试的只有 10 人, 而且有 4 人无法以汉语书 写, 但是余下的 6 人里有 3 人及格, 及格率为 $30 \%$, 比例明显较阅读卷高。再 者, 正如表七所示, 小宝、小云、小晴 3 人总分不及格其实是因为没有完成作 文中的“书信”部分。如不计算书信的 30 分, 3 人的分数分别为:

小宝: 评卷员甲: 35/70; 评卷员乙: $36 / 70$

小云: 评卷员甲: 46/70; 评卷员乙: $33 / 70$

小晴: 评卷员甲: 49/70; 评卷员乙: $35 / 70$

换言之, 三人的写作分数其实可算及格, 即写作卷模拟测试的整体及格率 可达 60\%, 是阅读模拟测试及格率的 9.6 倍! 是次的研究对象虽然属于方便取 样, 但是从最初的 21 所学校, 到后来只剩 5 所学校, 当中并非立意笁选, 实际 上是按学校的意愿和安排。而接受测试的学生更是按家长、教师及学生的意 愿, 并没有考虑学生日常的成绩和语文科表现。所以在阅读模拟测试中表现出 色的学生是否优等生与本文并无多大关连，反而同时接受阅读和写作模拟测试 的 10 位学生在阅读和写作两方面的表现值得我们深思。正如表八所示, 阅读和 写作模拟测试同时有理想表现的只有小玉和湘儿两人。另有四位学生在写作表 现不俗或尚算及格 (小红、小宝、小云、小晴), 但是在阅读卷的表现却明显失 色，只达总分的三分之一。

最后, 正如其中一位受访教师所强调的, 假设学生已有基本的写作能力 (冊须以英语作答), 则阅读理解的要求似乎较写作更为困难, 因为学生在写作 之时可以天马行空, 可以 “选择” 自己喜欢或懂得运用的生词, 但是面对阅读理 解的篇章, 却毫无 “选择” 可言, 是以较难有理想的表现。

\section{2 研究问题二的初步解答}

研究问题二：香港南亚裔小学生是否面对“朗读”的困难？如何有效解决学生的 学习困难?

首先, 先从教师访谈的结果加以分析。说话属于口语的范畴, 即 Jim Cummins (1994) 自 1990 年代以来提出的沟通技巧 (basic interpersonal communication skills, BICS), 第二语言学生较易掌握。朗读本来亦与说话相仿, 但是朗读内容往 往是课文或其他篇章, 所以其实与 “阅读” 的内容无异, 乃 Jim Cummins (1994) 所 言的学术能力 (cognitive / academic language proficiency, CALP), 第二语言学生 
需要较多时间方可学会。正如表五所示, 21 位受访教师中只有 3 位教师表示所教 南亚裔学生未能掌握汉语的“说”, 但超过一半的受访教师均以为南亚裔学生在朗 读方面有困难。

再根据学生访谈和观课所见, 正如表九所示, 研究对象对个人朗读其实颇为 抗拒，害怕会因发音错误被取笑或纠正。如果只问朗读的话，只有一半受访者表 示害怕，也有 4 成受访者表示有信心。但是谈到“个人朗读”，却7成表示害怕， 7 成没有信心, 7 成不喜欢。这跟全班朗读的 2 成害怕、9 成有信心及 6 成喜欢有 相当明显的差距。

研究问题二其中一部分是 “如何解决这些学习困难”。如果学生的学习困难 正如本文所发现的，“阅读” 和 “朗读” 是潜藏和容易被忽视的困难，则可以从 受访教师的访谈内容得到一点启示: “阅读就没有选择，他看不懂 “美丽” 就不明 白文章内容，就不懂怎样回答问题啊!”

学生的阅读理解分数比写作还低，原因在于日常的阅读量不够。除了课文以 外, 很少阅读其他文章, 所以作阅读理解时会遇上很多生词, 妨碍阅读和理解。 归根究底, 学生如能提升阅读量, 不但可以培养对汉语、对阅读的兴趣, 长远而 言更可以提升语文科的整体成绩。另一方面, 如要有较快的成效, 或许可以仿效 学校乙的教师那样, 训练学生的阅读策略, 以下三图 (图三、图四、图五), 撷 取自学校乙三位不同的学生的阅读卷模拟试题:

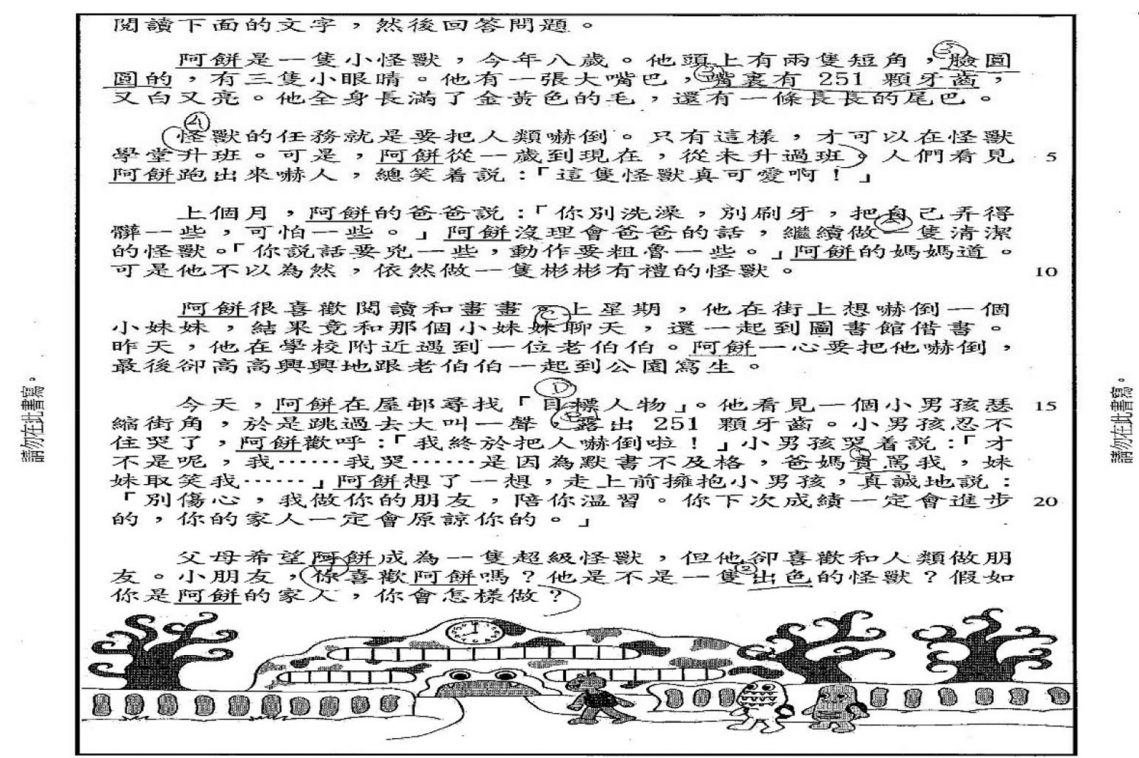

图三: 阅读策略例子 (一) 


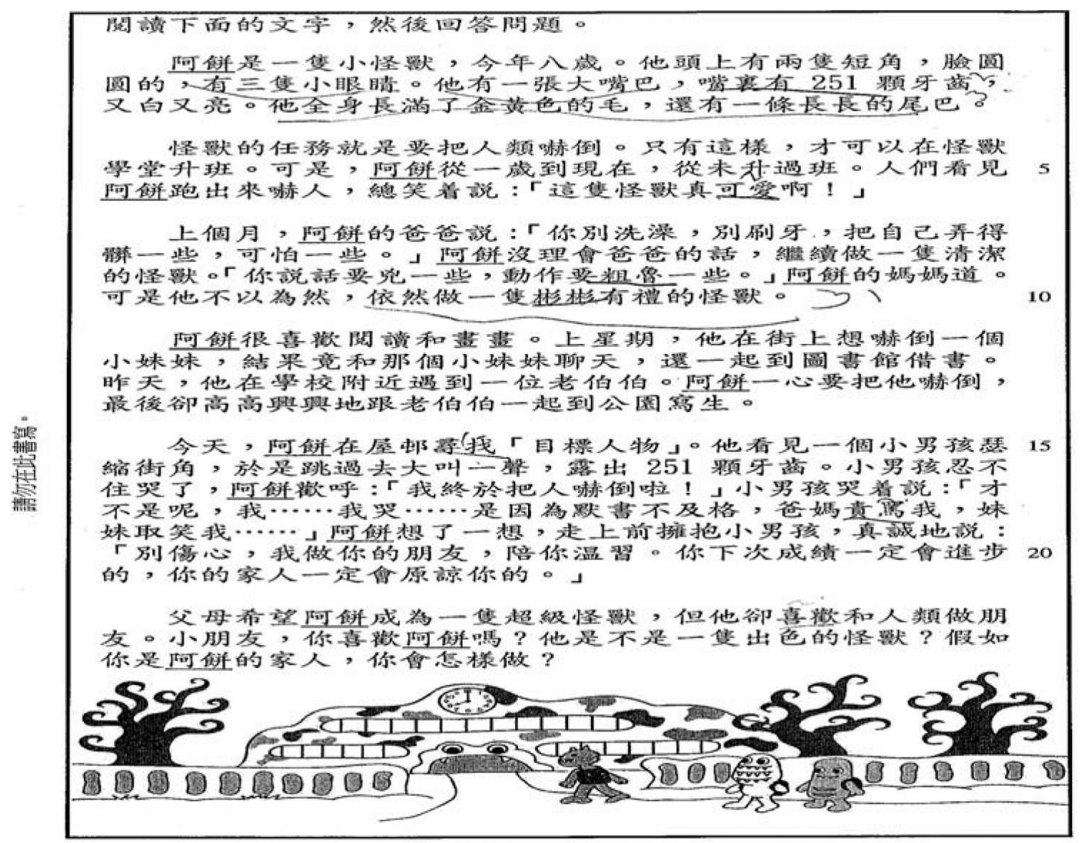

图四: 阅读策略例子（二）

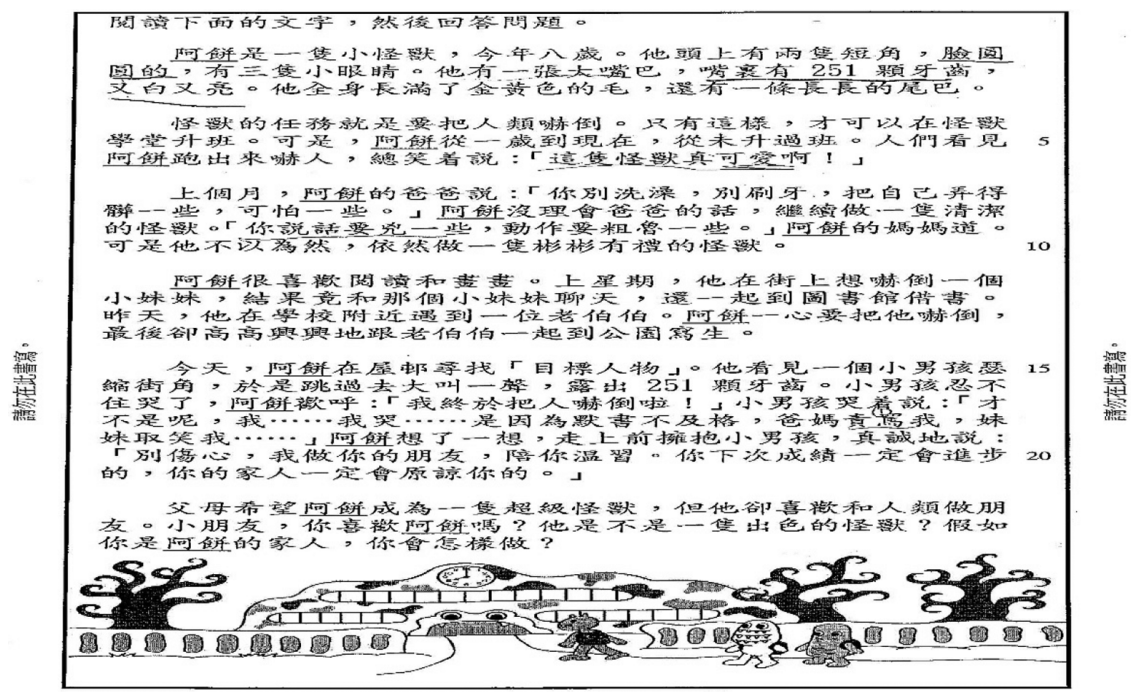

2012-TSA-CHON-3C-12Z-2

图五: 阅读策略例子 (三) 
图三、图四、图五所示三位学生明显在做阅读练习时习惯了要画下重点字 词、重心句子、记下问题答案等。图六所示为同一所学校化名为小玉的学生的 阅读卷答题, 该生取得了 19/24 的成绩, 是 32 位受试者中成绩最佳的其中一位 学生，她的答题卷更明显的使用了“排除”的答题技巧，如图六所示：

3. 下列哪兩項符合對阿䬼的描述? （請選擇兩個答案）

○一他的牙蒛既黑又镂。

B. 他有一張圆圆的脸。

○匹他有一雙小眼睛。

○同. 他的毛髮又白又毫。

E. E. 他有許多牙崡。

图六: 阅读策略例子之“排除”

由此可见, 如果 “阅读” 是南亚裔小学生的学习困难, 其实无关族裔, 同样可以 使用像华语学生那样的教学指导, 让学生提升阅读量和学习阅读和作答技巧, 自然有效提升阅读理解方面的成绩。

至于 “朗读”，反而跟族裔有更大的关连。因为 “阅读” 的困难，无论是华裔 还是非华裔, 只要阅读量不多, 只要不懂阅读和答题技巧, 一样会无法取得良好 成绩。但是 “朗读” 却跟南亚裔学生的母语有关, 他们较少接触汉语, 日常只使 用自己的母语或英语, 家人或朋友也多以南亚裔为主, 无法协助或纠正他们的发 音, 当遇上朗读 “课文” 这些日常很少接触的 “学术用语” (Cummins 1994) 时就会 较易缺乏信心，什至像其中一位受访者那样，推诿到自己的族裔身分之上：“我 是菲律宾人, 我干么要念汉语?”

如果真的要解决 “朗读” 这方面的困难, 其实可以考虑其中一位受访者那样的 积极态度: “我想参加朗诵比赛!”。哪怕不是所有学生都有如此正面的学习态度, 也可以考虑像其中一所学校那样举办朗读比赛, 提升学生的朗读意欲。此外, 教 师访谈以及表九所言的 “全班朗读”是最容易可行的方法。如果学生因为害怕被取 笑, 什至归处自己不是中国人, 所以发音不准, 那么透过全班一起朗读, 再由教 师悉心的教导和指正，相信对增强学生的朗读自信会有一定的果效。

\section{9 研究局限}

“麦理浩夫人中心” 的研究 (2013) 是以全港小学为研究对象, 并作随机抽样, 有 助提升研究的信度 (reliability) 和效度 (validity) (Cohen 2011; Lincoln and Guba 1985; Minichiello, Aroui, Timewell, Alexander 1990; Yin 2012)。然而, 本文只有 研究者一人, 两位评卷员只能在评卷方面满足三角印证 (triangulation), 至于数 据搜集和分析方面，最少有三方面的限制。 
第一、香港的学校大体可分为主流学校和国际学校 (立法会 2011a, 2012; 连 文尝、黄显华 2000) 两大类型。根据教育局 (2012) 的数字显示, 2011-2012 学 年, 全港有 40 所国际学校 (小学) 以及 528 所主流小学。主流小学中约五分之 二 (210 所) 为全华语学生, 另有五分之三 (318 所) 录取了合共 7,703 名非华语小 学生 (立法会 2011b：2446-2447; 2012; 香港教育局 2013：82)。本文取样的 21 所 学校并没有涵盖国际学校, 只能代表本港提供 “本地课程” 的官立、资助、直接 资助及私立小学四类 “主流学校” (平等机会委员会 2011) 为本港少数族裔 (非华 语) 学童提供教育的情况。

第二、本文的对象只有 21 所学校, 虽然以方便取样而言, 数目已颇为可观, 而且涵盖全港十八区中的十一区, 然而整体数字有限, 远未能推论至全港十八区 500 余所小学的实况。

第三、本文的测试部分并不平均, 阅读卷有 32 位学生参与, 写作卷则只有 10 位参与者。虽然比较二者的差别时可以从百分比入手, 但是写作卷如能有更 多的参与者, 相信可以提供更准确、更有说服力的数据。

\section{0 结语}

近年不少学者已明确指出, 南亚裔中学生的汉语学习困难以 “写” 为最, “读” 次 之。然而小学方面却没有这方面的系统性分析和研究。为此, 本文尝试以本港南 亚裔小学生为研究对象, 提出研究问题: 一、香港南亚裔小学三年级学生在阅读 和写作方面有何表现？二、香港南亚裔小学生是否面对 “朗读” 的困难？如何有 效解决学生的学习困难? 是次研究透过教师访谈、全港性系统评估模拟测试、学 生访谈、观课考查香港南亚裔小学三年级学生在 “写”、“读” (阅读、朗读) 方面 的表现, 希望提出有效解决学生学习困难的方法。

有关阅读和写作的问题，本文为了解答研究问题一，尝试透过教师访谈、全 港性系统评估模拟测试和学生访谈的研究方法。汉语字词的笔划、笔顺、结构等 与英语或其他南亚语言截然不同，对南亚裔学生而言无疑是一大难关。是次研究 在最初阶段的教师访谈中，亦得出南亚裔学生的写作问题较阅读更困难的统计数 据。但是随着研究者再邀请学生以全港性系统评估阅读及写作卷作模拟测试, 再 邀请学生访谈后, 却发现受试的南亚裔小三学生的写作能力较阅读更强。正如其 中一位受访教师所言, 南亚裔学生只要掌握了基本的汉语写字能力, 能以汉语作 答, 则写作其实比阅读更容易, 因为学生可以“选择”自己懂得运用的字词。反而 在阅读时, 由于阅读量不足，加以阅读理解的篇章往往出人意料，无法选择，故 学生的阅读问题较写作更值得关注。

至于“朗读”方面, 本文为了解答研究问题二, 尝试透过观课、教师及学生访 谈来考查南亚裔小三级学生的朗读问题, 发现朗读表面上属于 “说” 的范畴, 乃 Jim Cummins (1994) 所言的沟通能力, 是第二语言学习者较容易掌握的能力。 实际上因为朗读内容往往为较难掌握的学术用语, “其实是 “阅读” 困难的口语版 
本”。学生面对陌生的篇章, 既无法理解, 也难以朗读出来, 更因为害怕被同学 取笑、被教师纠正而对朗读心生畏惧。

本文只限于 21 所小学及 32 位小三学生, 调查的发现未能推论至全港小学, 更不能推翻对于南亚裔中学生而言, 写作是最大的难关这一项研究成果。但是 次研究结果明显指出受试者在掌握了一定的写字能力后, 则阅读的问题较写作 更严重。而朗读更是阅读问题的延续, 对南亚裔学生学习中文的信心、动力、 兴趣均有重大影响, 加之不在考核范围, 缺少训练和学习动机, 实在是南亚裔 学生以汉语作为第二语言的学习“隐忧”。

“写作”也许仍是南亚裔学生面对汉语学习的最大困难, 但是 “阅读” 和 “朗 读” 的困难却绝不容忽视, 正因为是 “隐忧”, 所以有时候反而更需要多加注意 和加以重视。文章的讨论部分最后提出一些改善南亚裔学生阅读和朗读表现的 建议方法, 希望能有效提升第二语言教师对学生这两方面 “潜伏” 困难的注意 力, 解决学生在阅读和朗读方面遇上的学习困难。

\section{附录}

\section{附录一：本港少数族裔学童教育情况调查 2012-13}

致 贵校科主任/负责人:

本港少数族裔学童的人数愈益增加, 为了掌握前线教师及学校在推行少数族裔 学童教育的实际情况, 现诚邀 贵校参与一项由香港圣公会麦理浩夫人中心少 数族裔服务部及香港大学合作的 “本港少数族裔学童教育情况” 调查, 贵校提 供的宝贵数据将以不记名的形式作计算机输入及分析, 有关数据将有助我们向 教育当局建议适切可行的支援措施予有需要的老师及少数族裔学生。

衷心感谢 贵校的协助! 所有数据, 绝对保密, 请放心回答。本调查需时约 5-10 分钟。

1. 贵校于本学年 2012/13 有否录取少数族裔 (非华语) 学童?

口有口没有 (请跳至最后一题)

如有, 请问共录取了多少名少数族裔学童? 一年级:

二年级: 人三年级: 人 四年级: 人 五年级: 人 六年级: 人

2. 少数族裔学童的族裔人数分布是多少? (请填上实际人数):

印度尼西亚: 人巴基斯坦: 人印度: 人 尼泊尔: 人 菲律宾: 人泰国: 南美洲: 人日本人: 人欧洲: 人北美洲: 人

其他 (请注明所属种族) :

3. 请问, 贵校的少数族裔 (非华语) 学童的男女比例大概是多少呢? 
4. 请问 贵校有多少本地学生（华语学生）? 人 全校的学生人数又是 多少? 人

5. 请问, 贵校的小三、小六非华语学生是否和其他华语学生一样会参与全港 性系统评估的考核（TSA）? 口是 口不是（请说明, 例如个别是, 个别不 是? 比例是多少?)

6. 贵校老师在教导少数族裔学童过程中有否遇到困难? (可选多项)

口少数族裔学童与教师语言不通, 未能沟通

口少数族裔学童学习能力、动机差异极大

口少数族裔学童的中文水平差异极大

口教师未能了解学童是否明白教学及对话内容

口不知道有甚么具体及有效教学方法, 要花费很多时间才能达到效果

口教师需要以简单英语作双语教学

口教师需要以大量英语作双语教学

口要顾及全班学生进度, 未能兼顾个别学童

口教师与少数族裔家长语言不通, 未能沟通

口少数族裔家长未能协助学童的课业

口其他 (请列明):

口没有困难

7. 贵校在行政上有否困难?

口有 (请说明: 口没有

8. 贵校有否需要剪裁中文课程, 以配合少数族裔学童的需要或中文程度?

口有 (请说明: ）没有

9. 贵校的教师曾否接受任教少数族裔学童的专业培训?

口有 (培训时数大约为 小时,

培训机构:

10. 贵校有否聘请少数族裔老师 / 助教 / 非教学人员协助日常教学和行政工作? 口有, 共有 名 口没有

11. 贵校为少数族裔学童提供的额外支援，包括哪些措施? (可选多项)

口聘请少数族裔人士担任教学/教学助理工作

口聘请少数族裔人士担任非教学工作 (如行政支援、家长沟通等)

口增聘整体人手

口为此类学童提供额外的中文班/课后功课辅导

口为此类学童提供特别的教材/学习材料

口为此类学童提供共融活动/课程

口其他 (请列明) :

口没有特别的支援，与本地生所获得的支援相同

12. 少数族裔学童最喜欢上甚么样的中文课? (可以 1，2，3，4，5 排序)

$\square$ 故事 $\square$ 戏剧 $\square$ 诗歌 $\square$ 童谣 $\square$ 其他（请注明:

您认为原因何在? 
13. 少数族裔学童最不喜欢上甚么样的中文课? (可以 1，2，3，4，5排序)

$\square$ 故事 $\square$ 戏剧 $\square$ 诗歌 $\square$ 童谣 $\square$ 其他（请注明:

您认为原因何在?

14. 少数族裔学童在中文科的哪一方面表现最好? (可以 1, 2, 3, 4, 5 排序)

$\square$ 听 $\square$ 说 $\square$ 读 $\square$ 写 $\square$ 其他

（请注明:

您认为原因何在?

15. 少数族裔学童在中文科的哪一方面表现最差? (可以 1，2，3，4，5 排序)

$\square$ 听 $\square$ 说 $\square$ 读 $\square$ 写 $\square$ 其他

（请注明:

16. 您认为如何可以提升少数族裔学童学习中文的兴趣?

17. 您认为少数族裔学童学习中文有甚么困难?

18. 您认为让少数族裔学童与华语学生一起学习中文是不是一个正确的方向/ 政策?

口是 口不是

原因是甚么?

如答案为 “是”，那华语生和非华语生理想的比例是多少呢?

\section{附录二: 香港圣公会麦理浩夫人中心少数族裔服务部 2013 研 究的相关数据}

表十: 受访学校总数及受访者职衔

\begin{tabular}{|c|c|c|c|}
\hline 受访者职衔 类别 & 录取少数族裔学生 & 没有录取少数族裔学生 & 总数 \\
\hline 主管 / 校长 & 2 & 2 & 4 \\
\hline 副校长 / 助理校长 & $5^{*}$ & 0 & 5 \\
\hline 教务主任 ～～～ & 1 & 0 & 1 \\
\hline 课程统筹主任 & 1 & 1 & 2 \\
\hline 中文科科主任 & $30 * \star$ & 26 & 56 \\
\hline 中文科副科主任 & 0 & 1 & 1 \\
\hline 中文科老师 & 2 & 0 & 2 \\
\hline 受访学校总数 & 41 & 30 & 71 \\
\hline
\end{tabular}

*其中一位副校长在 2013 年 9 年升为校长

**其中一位科主任在 2013 年 9 年升为助理校长 
表十一: 受访学校的地域分布

\begin{tabular}{lr}
\hline 九龙城区 & 5 \\
中西区 & 10 \\
元朗区 & 6 \\
屯门区 & 6 \\
北区 & 6 \\
沙田区 & 4 \\
东区 & 2 \\
油尖旺区 & 4 \\
南区 & 3 \\
荃湾区 & 3 \\
深水埗区 & 6 \\
黄大仙区 & 2 \\
葵青区 & 9 \\
离岛区 & 2 \\
观塘区 & 3 \\
总数 & 71 \\
\hline
\end{tabular}

表十二: 录取少数族裔 (非华语) 学

生的受访学校的地域分布

\begin{tabular}{lr}
\hline 九龙城区 & 1 \\
中西区 & 7 \\
元朗区 & 4 \\
屯门区 & 4 \\
北区 & 2 \\
沙田区 & 1 \\
东区 & 1 \\
油尖旺区 & 3 \\
南区 & 3 \\
荃湾区 & 1 \\
深水埗区 & 4 \\
葵青区 & 8 \\
离岛区 & 1 \\
观塘区 & 1 \\
& 41 \\
\hline
\end{tabular}

\section{参考文献}

岑绍基、戴忠沛， 2013，香港非华语学生中文书写能力分析一一香港大学 “学生支援计划” 记叙文前测后测表现为例。《第四届 “汉字与汉字教育” 国际研讨会》, 香港: 香港大学。 
岑绍基、张燕华、张群英、祁永华及吴秀丽, 2012, 香港少数族裔学生学习中文的困难。见从 铁华、岑绍基、祁永华及张群英编《香港少数族裔学生学习中文的研究》。香港: 香港大 学出版社, 53-75 页。

岑绍基, 2012a, 《从阅读中学习: 用文类教学法提高主流学校非华语学生的读写能》。 《“面向跨文化学习者的中文学与教：挑战与突破”研讨会》，香港：香港大学。

岑绍基, 2012b, 序三。见谢锡金、祁永华、岑绍基编《非华语学生的中文学与教：课程、教

材、教法与评估》, 香港: 香港大学出版社, xiii-xiv 页。

丛铁华、岑绍基、祁永华、张群英编着, 2012, 《香港少数族裔学生学习中文的研究》。香 港: 香港大学出版社。

关之英、马帼英, 2009, “非华语学童”学中文的多媒体教材设计。CIS 25th DUAL-LANGUAGE SYMPOSIUM, 香港。

关之英, 2008a, 香港伊斯兰学童学中文的优势和困难。《建道学刊》第 29 期, 73-88 页。 关之英, $2008 \mathrm{~b}$, 中文作为第二语言: 教材及教法的设计理念与实践。《2008 亚洲太平洋地区 华语文教学与发展国际学术研讨会》, 台湾。

关之英, 2010, 语文学习的鹰架: 中文作为第二语言教学的课堂研究。《中文教师学会学 报》第 45 期(3), 67-103 页。

黄敏洪, 2012, 香港非华语学生学习书写汉字的困难。Research Higher Degree - Student Seminar (13 November 2012), 香港: 香港大学。

黄汝嘉、萧宁波, 2009, 香港少数族裔小学生的中文能力水平。《基础教育学报》第 18 期(2), 123-136 页。

霍立德, 2013, 〈追撃〉融合教育。《教协报》 (大专版), 2013 年 5 月 27 日。

家庭与学校合作事宜委员会, 2012, 《小学概览》。http://www.chsc.hk/psp2012/main.php? lang_id=2 (2013 年 4 月 13 日测览)

李浚龙, 2010, 教授小学非华语学生中文识字的课堂学习研究。Research Higher Degree Student Seminar (20th March 2010), 香港: 香港大学。

立法会, 2011a, 《立法会会议过程正式纪录 (7.12.2011)》。香港: 香港特别行政区立法会。 http://www.legco.gov.hk/yr11-12/chinese/counmtg/hansard/cm1207-translate-c.pdf (2012 年 9 月 11 日汶览)。

立法会, 2011b, 《立法会会议过程正式纪录 (14.12.2011)》。香港: 香港特别行政区立法会。 http://www.legco.gov.hk/yr11-12/chinese/counmtg/hansard/cm1214-translate-c.pdf （2012 年 9 月 11 日汶览）。

立法会, 2011c, 《立法会会议过程正式纪录 (27.10.2011)》。香港: 香港特别行政区立法会。 http://www.legco.gov.hk/yr11-12/chinese/counmtg/hansard/cm1027-translate-c.pdf (2012 年 9 月 11 日浏览)。

立法会, 2012, 《立法会会议过程正式纪录 (14.11.2012)》。香港: 香港特别行政区立法会。 http://www.legco.gov.hk/yr12-13/chinese/counmtg/hansard/cm1114-translate-c.pdf (2013 年 5 月 28 日汶览)。

连文尝、黄显华, 2000, 《教育改革的核心问题: 学习的性质一一从主流小学到国际小 学》。香港: 香港中文大学教育研究所。

民政事务局, 2000, 《有关香港少数族裔人士特征的抽样调查》 (CB(2)590/00-01(01) 号文件)。香港: 香港特别行政区立法会。http://www.legco.gov.hk/yr00-01/chinese/panels/ ha/papers/590c01.pdf (2013 年 7 月 2 日汶览)。

平等机会委员会, 2011, 《人人有书读》。香港:平等机会委员会。http://www.eoc.org.hk/ EOC/Upload/UserFiles/File/rdo/education/rdo_edu_chi.pdf (2013 年 7 月 3 日浏览)。

祁永华, 2012, 有关的历史和社会脉络。见谢锡金、祁永华、岑绍基编《非华语学生的中文学 与教: 课程、教材、教法与评估》。香港: 香港大学出版社, 3-13 页。 
容运珊, 2013a, 《“以读促学”教学法对提高香港非华语中学生中文写作能力的成效》。

Research Higher Degree - Student Seminar (5th July 2013) , 香港: 香港大学。

容运珊, 2013b, “以读促学”教学法在香港非华语中学生中文论说文写作教学的实施成效。 《第四届“汉字与汉字教育”国际研讨会》, 香港: 香港大学。

香港教育局, 2012, 《小学教育》, 2012 年 6 月 25 日更新。http://www.edb.gov.hk/tc/aboutedb/publications-stat/figures/pri.html（2013 年 3 月 19 日汶览）。

香港教育局, 2013, 《财务委员会审核二零一三至一四年度开支预算管制人员的答复》。香 港: 香港教育局。http://www.edb.gov.hk/attachment/tc/about-edb/publications-stat/figures/edb-c.pdf\#page $=215$ (2013 年 5 月 9 日汶览)。

香港融乐会, 2011, 《回应教育局提交立法会教育事务委员会之讨论文件》(立法会 CB(2)570/ 11-12(01) 号文件)。香港: 香港融乐会有限公局.

香港圣公会麦理浩夫人中心, 2013, 《本港少数族裔学童教育情况调查 2012-13》。香港: 香 港圣公会麦理浩夫人中心。

谢锡金、祁永华、岑绍基, 2012a, 《非华语学生的中文学与教：课程、教材、教法与评估》。 香港: 香港大学出版社。

谢锡金、祁永华、岑绍基, 2012b, 鸣谢。见谢锡金、祁永华、岑绍基编《非华语学生的中文 学与教: 课程、教材、教法与评估》。香港: 香港大学出版社, xv-xvii 页。

语文教育及研究常务委员会, 2012, 《语常会支援非华语儿童学习中文试验计划》招标 (附 件）。香港: 香港特别行政区政府教育局语文教育及研究常务委员会。

袁振华, 2007, 《香港南亚裔学生中文学习的困境及对策研究》。华中师范大学语言学及应用 语言学博士论文。

政府统计处, 2006, 《主题性报告: 少数族裔人士》。香港: 香港特别行政区政府统计处。 http://www.statistics.gov.hk/publication/stat_report/population/ B11200502006XXXXB0100.pdf（2012 年 5 月 31 日汶览）。

政府统计处, 2012a, 《2011 人口普查简要报告》。香港: 香港特别行政区政府统计处。 http://www.census2011.gov.hk/pdf/summary-results.pdf (2012 年 6 月 13 日汶览)。

政府统计处, 2012b, 《主题性报告: 少数族裔人士》。香港: 香港特别行政区政府统计处。 http://www.census2011.gov.hk/pdf/EM.pdf (2013 年 3 月 19 日汶览)。

Cohen, L. 2011. Research methods in education (7th ed.). Abingdon, Oxon; New York: Routledge.

Connelly, J., Gube, J., and Thapa, C. 2013. Contradictions in Hong Kong's policy of support measure for ethnic and linguistic minority students. Education, Ethnicity, and Inequality: Issues and Insights Symposium, Hong Kong.

Cummins, J. 1994. The acquisition of English as a second language. In: K. SpangenbergUrbschat, R. Pritchard (eds.) Reading instruction for ESL students. Delaware: International Reading Association.

Education Bureau 2011. Whole School Approach to integrated Education. Hong Kong: Education Bureau. Retrieved from http://www.edb.gov.hk/index.aspx?nodelD=7348\%26langno=1.

Hong Kong Unison Limited 2012. Kindergarten Education for Ethnic Minority School children (LC Paper No. CB(2)1706/11-12(01)). Hong Kong: Hong Kong Unison Limited.

Leung, C. 2003. Integrating School-Aged ESL Learners into the Mainstream Curriculum. Urban Language \& Literacies paper 21. London: King's College.

Leung, C. 2007. Integrating School-aged ESL learners into the mainstream curriculum. In: J. Cummins and C. Davison (eds.) International handbook of English language teaching (Vol. 1). New York: Springer, 249-270.

Lincoln, Y. S., and Guba, E. G. 1985. Naturalistic inquiry. Beverly Hills: Sage Pubns. Minichiello, V., Aroui, R., Timewell, E., and Alexander, L. 1990. In-depth interviewing: researching people. Melbourne: Longman Cheshire. 
Poon, A. Y. K. 1998. Investigating Hong Kong's Medium of Instruction Policy Proposed in the Education Commission Report No. 4 in 1990. PhD Thesis, Queensland University of Technology.

Poon, A. Y. K. 2000. Medium of Instruction in Hong Kong: Policy and Practice. Maryland: University Press of America.

Tse, S. K., Lam, W.-I., Cheung, W. M., Ki, W. W., Shum, S. K. et al. 2012. From School-based Support to Good Practices. Hong Kong: The University of Hong Kong.

Wong, Y. K. 2010. Acquisition of Chinese Literacy by Ethnic Minority Children in Hong Kong Primary Schools. EdD Thesis, Chinese University of Hong Kong.

Yin, R., K. 2012. Applications of case study research (3rd ed.). California: SAGE.

\section{Bionote}

\section{Priscilla Chou}

Priscilla Chou is a PhD candidate at the University of Hong Kong (HKU) with research interests in Chinese Language and literatures, the learning of Chinese as a second language, education issues of ethnic minorities in Hong Kong, etc. 